\title{
Modelling of Particle Dispersion in Mechanically Ventilated Space
}

\author{
Ismail Abdul Rahman ${ }^{1}$, Jouvan Chandra Pratama Putra ${ }^{1} \& \mathrm{Ade} \mathrm{Asmi}^{2}$ \\ ${ }^{1}$ Faculty of Civil and Environmental Engineering, Universiti Tun Hussein Onn Malaysia (UTHM), Malaysia \\ ${ }^{2}$ Faculty of Civil Engineering, Bakrie University, Indonesia \\ Correspondence: Jouvan Chandra Pratama Putra, Faculty of Civil and Environmental Engineering, Universiti \\ Tun Hussein Onn Malaysia (UTHM), Malaysia. E-mail: jouvanchandra@gmail.com
}

Received: October 10, 2013 Accepted: February 10, 2014 Online Published: April 8, 2014

doi:10.5539/mas.v8n3p60 URL: http://dx.doi.org/10.5539/mas.v8n3p60

\begin{abstract}
This study presents simulation works carried out regarding to the airflow movement and particle dispersion in mechanically ventilated laboratory space at Faculty of Civil and Environmental Engineering of Universiti Tun Hussein Onn Malaysia. The measurement of air velocity was taken using Anemometer kit 4 in 1 while the particle dispersion was measured using Met-One Particle Counter GT-521 and measured at random points. The measured air velocity and particle dispersion are then used as input in simulation work using Comsol Multiphysics software. The simulation results are validated with the measured value and found that the percentage differences are within $6-10 \%$ which is accepted by many researchers. This study found that the amount of particle dispersion increased toward the corner of the space and concurrently with the airflow movement. This is indicates that the particle dispersion depends on the airflow movement.
\end{abstract}

Keywords: Comsol Multiphysics, particle dispersion, airflow movement

\section{Introduction}

Modeling is process of emulating a real system (Robinson, 2007), while simulation is the process of manipulating of the model for the purpose of understanding the behavior of the system or for evaluating various strategies for the operation of the system (Shannon, 1975). The advantage of modeling is that it able to combine several physic phenomena into a single entity (COMSOL, 2007). Modelling also able to carried out analysis using several approaches for getting appropriate solution(Pryor, 2011).

Malaysia, as a country which has a hot and humid climate (Yau, Chew, \& Saifullah, 2012) is essential to provide thermal comfort during office hours. Air-conditioning is one of mechanical ventilation system that widely used to provide it (Ismail et al., 2009). However, mechanical ventilation system is could be associated with IAQ problems such high levels of air contaminants due to the insufficient of airflow (Meckler, 1991). For IAQ assessment, modeling and simulation of indoor particle dispersion is important to assess for better prediction of human exposure to particle pollutants (Abadie \& Limam, 2007). Indoor particle concentration is affected by the inhomogeneous of airflow that generated through ventilation system and effected to the health of people (Mendonça, Abadie, \& Blondeau, 2012).

Previously, there are several studies on particle dispersion in mechanically ventilated space using modelling and simulation software (Cheong et al., 2003; Chung, 1995; Tian, Tu, Yeoh, \& Yuen, 2006). Cheong et al. (2003) used Computational Fluid Dynamic (CFD) software to simulate particle dispersion in air-conditioned room by adopting the Re-Normalization Group (RNG) as k- $\varepsilon$ turbulence model. The simulation results indicated that the patern of particle dispersionis highly dependent on the air velocity flow. Chung (1995) investigated the air movement and particle transport in partitioned enclosure by using EXACT3 software. The software using k- $\varepsilon$ model to simulate the airflow, while Brownian-motion is adopted for simulates particle dispersion. The results indicated that the path of particle depends greatly on the region of room where it originates. Besides, it is also found that particle dispersion in the range of $0.1-1.0 \mu \mathrm{m}$ were not affected by their different diameters. Tian et al. (2006), numerically investigated particle dispersion indoor through FLUENT software. To simulate the indoor

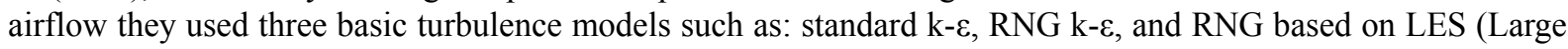
Eddy Simulation), while the particle distribution was simulated using the Lagrangian particle-tracking model. The results indicated that the RNG based LES model provided the best agreement for Low-Reynolds-Number (LRN) turbulence indoor airflow, while the Lagrangian particle-tracking model for particle distribution indoor. 


\section{Measurement of Particle}

This study was carried out on mechanically ventilated laboratory at Faculty of Civil and Environmental Engineering of Universiti Tun Hussein Onn Malaysia (UTHM). Measurement of particles dispersion and air velocity were conducted for eight hours duration for one day. The number of samples in this laboratory is 20 as respect to the Equation 1.

$$
\mathrm{N}_{\mathrm{L}}=\sqrt{\mathrm{A}}
$$

Where;

$\mathrm{N}_{\mathrm{L}}$ : The minimum number of sampling locations.

A: The area or zone in square meter $\left(\mathrm{m}^{2}\right)$.

Measurement of samples was carried out using two types of equipment. For particle dispersion, equipment used is Met One Particle GT-521 which is used to measure Particulate Matter (PM) $\geq 0.3 \mu \mathrm{m}$, while Anemometer kit 4 in 1 to measure the air velocity. Prior to the measurement, all the equipments are calibrated according to GT-521-9800 Rev D standard (Met One Instruments Inc., 2001) for accurate measurement.

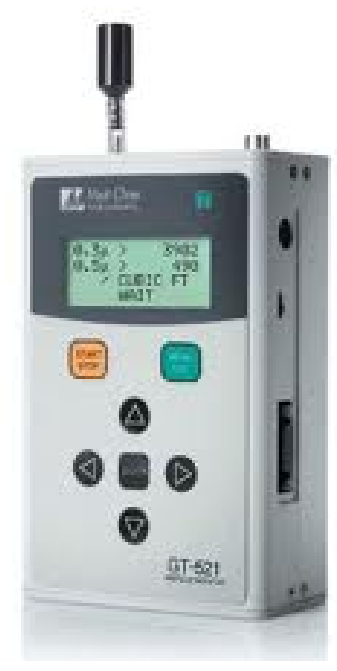

Figure 1. Met one particle counter GT-521

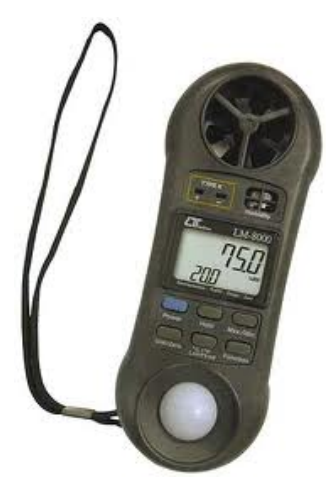

Figure 2. Anemometer kit 4 in 1

\section{Modelling of Particle Distribution}

Modelling process involved several steps which include selecting application mode, assigning constant parameters, creating geometry, meshing, and selecting solver parameter and running the simulation. For this study, the selected module is $\mathrm{k}-\varepsilon$ analysis in application mode of chemical engineering of Comsol Multiphysics software. This module adopted Navier-Stokes equation which is characterized by density of air, dynamic viscosity, velocity of air, pressure, and gravity as in Equation 2.

$$
\rho \frac{d u}{d t}-\nabla \cdot\left[\eta\left(\nabla \mathrm{u}+(\nabla \mathrm{u})^{\mathrm{T}}\right)\right]+\rho(\mathrm{u} . \nabla) \mathrm{u}+\nabla \mathrm{p}=\mathrm{F}
$$

Where;

- $\quad \eta$ is the dynamic viscosity $(\mathrm{kg} / \mathrm{m} . \mathrm{s})$.

- $u$ is the velocity $(\mathrm{m} / \mathrm{s})$.

- $\rho$ is the density $\left(\mathrm{kg} / \mathrm{m}^{3}\right)$.

- $\mathrm{p}$ is the pressure $(\mathrm{Pa})$.

- $\mathrm{F}$ is a volume force such as gravity $\left(\mathrm{m} / \mathrm{s}^{2}\right)$.

For modelling particle dispersion, mass transportation module with Lagrangian analysis in application mode of chemical engineering in Comsol Multiphysics software was selected. This module used diffusion equation which is characterized by mass concentration, diffusion coefficient, and reaction rate as formulated in Equation 3. 


$$
\partial \frac{\partial c}{\partial t}+\partial(-\mathrm{D} \partial \mathrm{c})=\mathrm{R}
$$

Where;

- $\mathrm{C}$ is the mass concentration $\left(\mathrm{mol} / \mathrm{m}^{3}\right)$.

- $\mathrm{D}$ is the diffusion coefficient $\left(\mathrm{m}^{2} / \mathrm{s}\right)$.

- $\mathrm{R}$ is the reaction rate $\left(\mathrm{mol} / \mathrm{m}^{3}\right)$.

Once the parameters in Navier-Stokes and diffusion equation were filled, then meshing was carried out to divide the geometry model into smaller shape or area. To solve mesh problem, solver parameter is needed and for this study Direct (Pardiso) linear system solver was used. This solver was selected because it is more efficient in memory storage for 2D analysis as compared to other solver parameters in 2D such as Direct (UMFPACK) and Direct (SPOOLES).

\subsection{Air Movement}

Modelling process of air movement involved 778 elements with 7,091 degree of freedom solved within 32.503 $\mathrm{sec}$ as shown in Figure 3. The simulation result shows that, the maximum of air velocity in this laboratory is $1.272 \mathrm{~m} / \mathrm{s}$, while the air velocity at the occupant's location is in the range of $0.005 \mathrm{~m} / \mathrm{s}$ to $0.43 \mathrm{~m} / \mathrm{s}$. For airflow estimation, the air velocity at the occupant's location is multiplied with its area. Thus, the estimated airflow for this laboratory is in the range of $6.05 \mathrm{~m}^{3} / \mathrm{s}$ to $52.03 \mathrm{~m}^{3} / \mathrm{s}$. The airflow movement is originated through inject airflow from air-conditioning system and distributed to the laboratory space where the airflow movement was mostly distributed to the corner as depicted in Figure 4. The rate of ventilation is calculated by dividing estimated airflow with the number of occupant. Hence, for this laboratory the rate of ventilation calculated is in the range of $302.5 \mathrm{l} / \mathrm{s} / \mathrm{p}$ to $2,601.5 \mathrm{l} / \mathrm{s} / \mathrm{p}$.

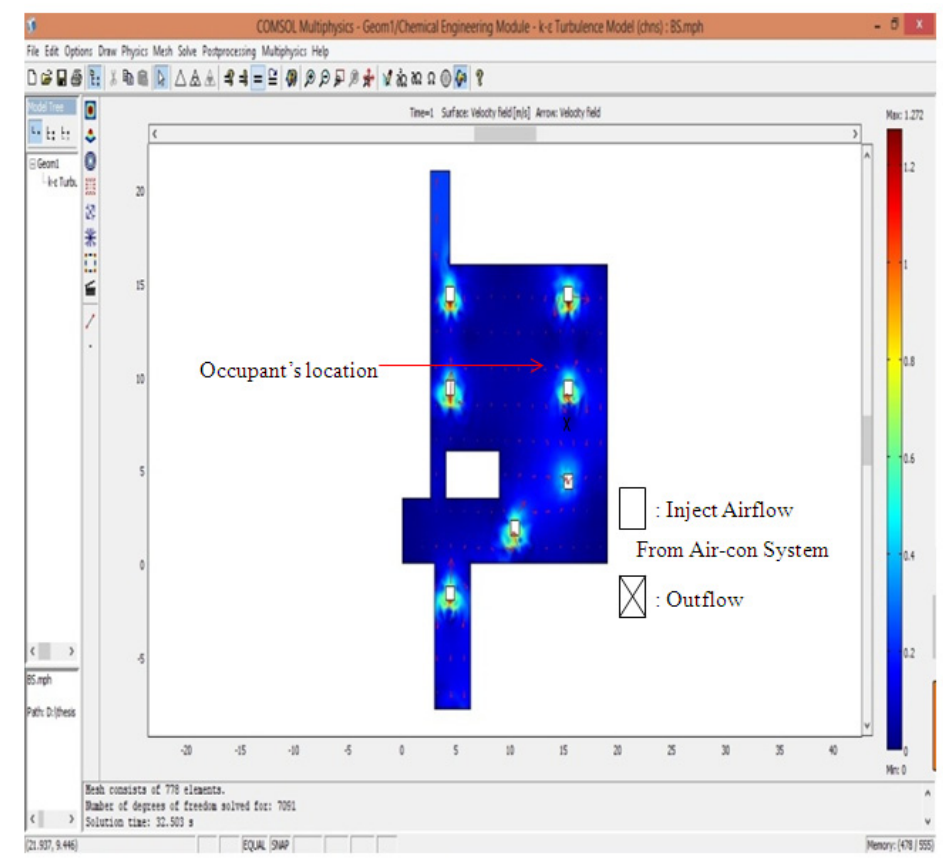

Figure 3. Air velocity distribution

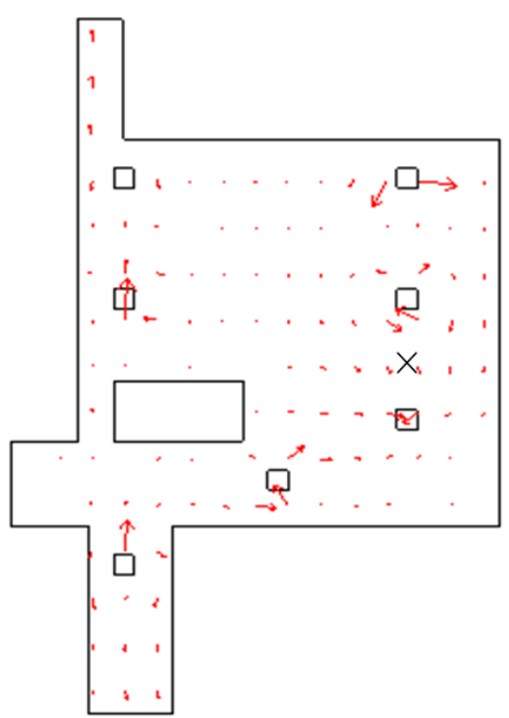

Figure 4. Airflow movement

Average hourly data of air velocity distribution generated from the simulation was compared with the measured average hourly data for validation purpose. The comparison of the average hourly data for duration of eight hours is as shown in Figure 5. The measured value is below than the simulated value with percentage difference range from $6 \%$ to $9 \%$ as in Table 1 . 


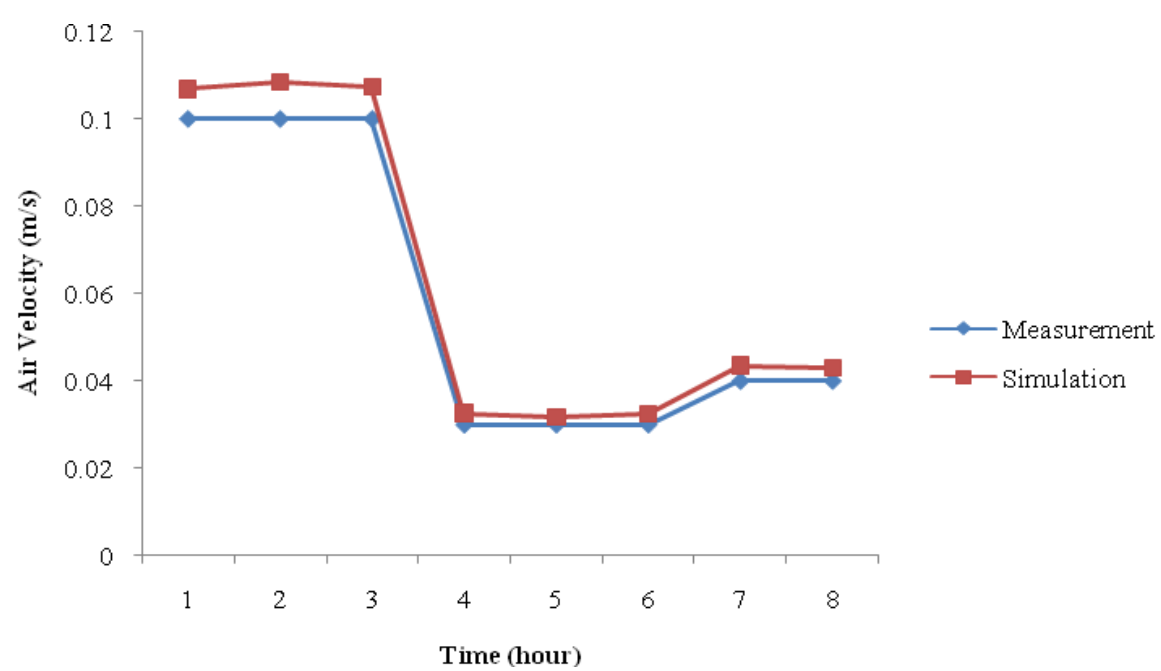

Figure 5. Measured vs. simulated of air velocity

Table 1. Percentage difference between measurement and simulation results

\begin{tabular}{cllc}
\hline \multirow{2}{*}{ Hours } & \multicolumn{2}{c}{ Air Velocity $(\mathrm{m} / \mathrm{s})$} & \multirow{2}{*}{ PD (\%) } \\
\cline { 2 - 3 } & Measurement & Simulation & \\
\hline 1 & 0.1 & 0.107 & 7 \\
2 & 0.1 & 0.1085 & 8.5 \\
3 & 0.1 & 0.1075 & 7.5 \\
4 & 0.03 & 0.0327 & 9 \\
5 & 0.03 & 0.0318 & 6 \\
6 & 0.03 & 0.0324 & 8 \\
7 & 0.04 & 0.0436 & 9 \\
8 & 0.04 & 0.043 & 7.5 \\
\hline
\end{tabular}

\subsection{Particle Dispersion}

For particle dispersion with size $\geq 0.3 \mu \mathrm{m}$, the modelling process involved 778 elements with 1,663 degree of freedom solved within $27.5 \mathrm{sec}$ as in Figure 6. The figure shows dispersion of the particle in the laboratory where the maximum value of particle dispersion is $4.532 .10^{-16} \mathrm{~mol} / \mathrm{m}^{3}$ which is equal with $272,826,400$ particle $/ \mathrm{m}^{3}$, while the minimum value of particle dispersion is $1.483 .10^{-16} \mathrm{~mol} / \mathrm{m}^{3}$ which is equal with $89,276,600$ particle $/ \mathrm{m}^{3}$. The dispersion of particle is increasing in the corner of this laboratory as shown in Figure 7, where it location is quite far from air-conditioning system. 


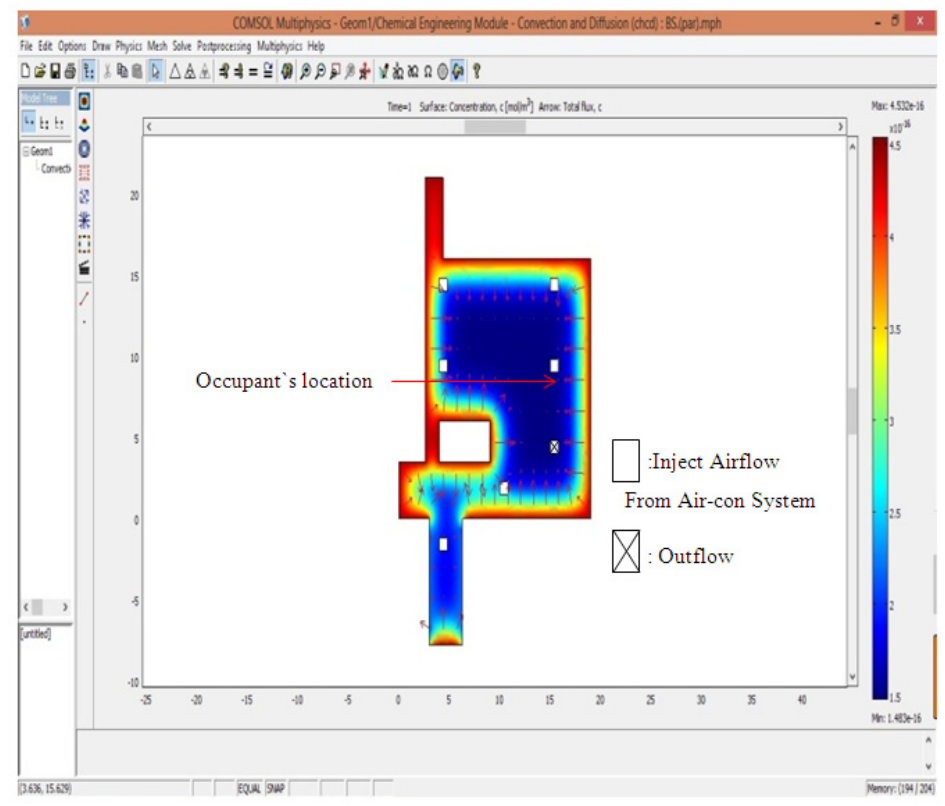

Figure 6. Particle dispersion

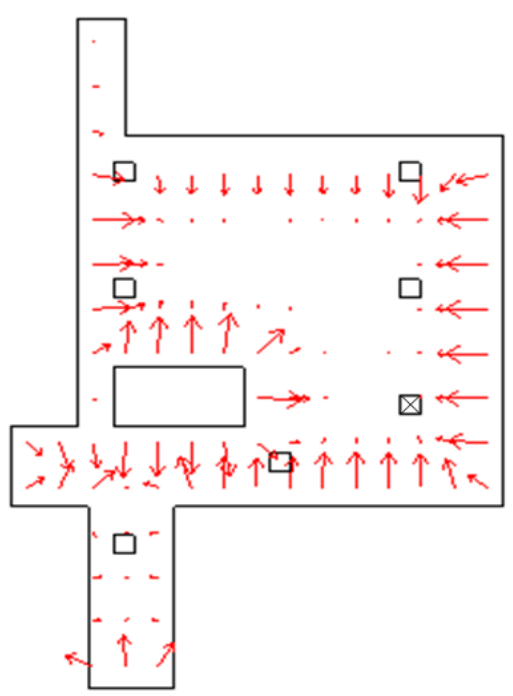

Figure 7. Path of particle dispersion

Beside air velocity, the comparison is also on particle dispersion. The average hourly data for particle dispersion simulated and measured within duration of eight hours are as shown in Figure 8. Differences of the values are in the range of $6.7 \%$ to $10 \%$ as in Table 2 .

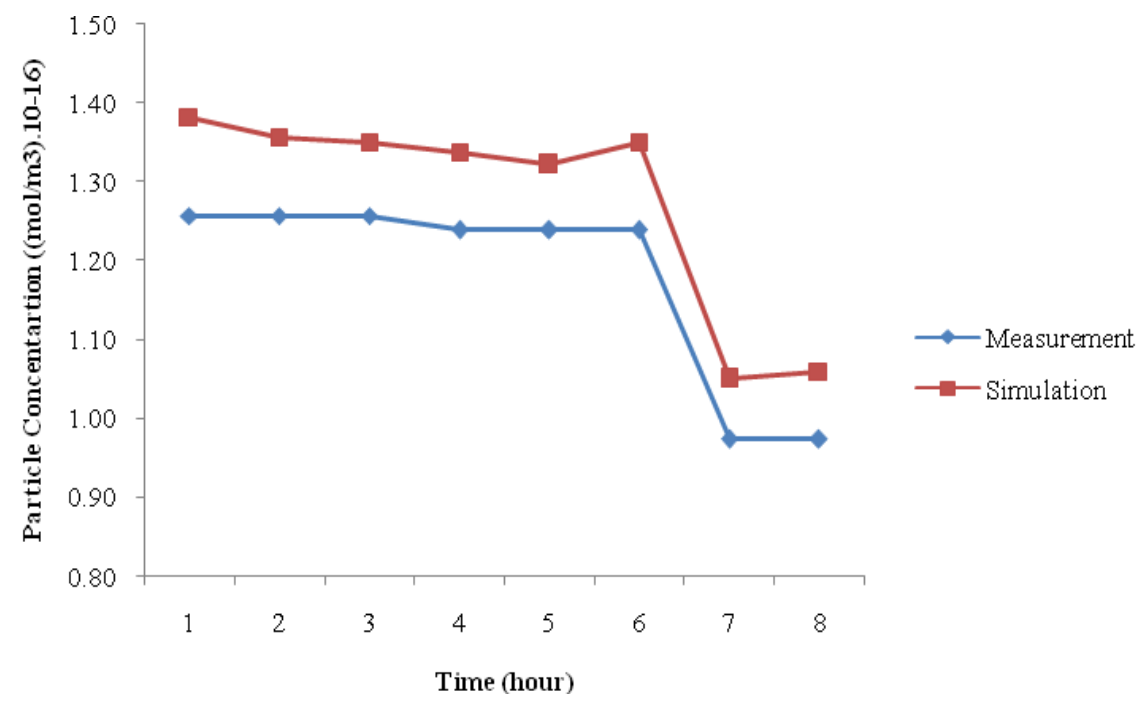

Figure 8. Measured vs. simulated of particle dispersion 
Table 2. Percentage difference between measurement and simulation results

\begin{tabular}{cccc}
\hline \multirow{2}{*}{ Hours } & \multicolumn{2}{c}{ Particle Distribution $\left(\mathrm{mol} / \mathrm{m}^{3}\right)$} & \multirow{2}{*}{ PD (\%) } \\
\cline { 2 - 3 } & Measurement & Simulation & \\
\hline 1 & $1.2569 \mathrm{E}-16$ & $1.383 \mathrm{E}-16$ & 10 \\
2 & $1.2569 \mathrm{E}-16$ & $1.357 \mathrm{E}-16$ & 8 \\
3 & $1.2569 \mathrm{E}-16$ & $1.351 \mathrm{E}-16$ & 7.5 \\
4 & $1.23924 \mathrm{E}-16$ & $1.338 \mathrm{E}-16$ & 8 \\
5 & $1.23924 \mathrm{E}-16$ & $1.322 \mathrm{E}-16$ & 6.7 \\
6 & $1.23924 \mathrm{E}-16$ & $1.351 \mathrm{E}-16$ & 9 \\
7 & $9.74 \mathrm{E}-17$ & $1.05 \mathrm{E}-16$ & 7.8 \\
8 & $9.74 \mathrm{E}-17$ & $1.06 \mathrm{E}-16$ & 8.8 \\
\hline
\end{tabular}

According to Chowdhury et al. (2008), and Judkoff et al. (2008), tolerable percentage difference is in the range of $6-10 \%$. Hence, this is within the suggested tolerance. The discrepancy of air velocity and particle dispersion maybe due to the dissimiliarities of air density, dynamic viscosity, diffusion coefficient, and reaction rate applied in Comsol Multiphysics model.

From the simulation results, particle dispersion is influenced by airflow movement of the space. The dispersion is lesser at the centre of the space due to presence of diffuser which discharges the airflow and causing the particle spreading to the corner of the space. The result of this simulation works found that the ventilation rate of the space is in the range of $302.5 \mathrm{l} / \mathrm{s} / \mathrm{p}-2,601 \mathrm{l} / \mathrm{s} / \mathrm{p}$ and this meet with ASHRAE standard of minimum ventilation rate for indoor space which is $10 \mathrm{l} / \mathrm{s} / \mathrm{p}$.

\section{Conclusions}

This study demonstrates the simulation works regarding the airflow movement and particle dispersion using Comsol Multiphysics software. It is to assess the influence of air movement towards particle dispersion in a well ventilated space. The simulated results are validated with the measured value and found that the percentage differences are within $6-10 \%$ which is accepted by many researchers. This study found that the amount of particle dispersion increased toward the corner of the space and concurrently with the airflow movement which is similar with finding from (Cheong et al., 2003). This is indicates that the particle dispersion depends on the airflow movement.

\section{Acknowledgements}

Thanks and gratitude to Ministry of Higher Education Malaysia and Research and Innovation Centre of Universiti Tun Hussein Onn Malaysia for funding this paper under Short Term Grant (STG) vote 1073.

\section{References}

Abadie, M. O., \& Limam, K. (2007). Numerical evaluation of the particle pollutant homogeneity and mixing time in a ventilated room. Building and Environment, 42(11), 3848-3854. http://dx.doi.org/10.1016/j.buildenv.2006.11.010

Bambang, B. P. (2008). Analysis of Natural Ventilation at Meeting Room of Physics Engineering and Residential House. Bandung Institute of Technology.

Cheong, K. W. D., Djunaedy, E., Poh, T. K., Tham, K. W., Sekhar, S. C., Wong, N. H., \& Ullah, M. B. (2003). Measurements and computations of contaminant's distribution in an office environment. Building and Environment, 38, 135-145. http://dx.doi.org/10.1016/S0360-1323(02)00031-8

Chowdhury, A. A., Rasul, M. G., \& Khan, M. M. K. (2008). Thermal-comfort analysis and simulation for various low-energy cooling-technologies applied to an office building in a subtropical climate. Applied Energy, 85(6), 449-462. http://dx.doi.org/10.1016/j.apenergy.2007.10.001

Chung, K. C. (1995). Three dimensional analysis of airflow and contaminant particle transport in a partitioned enclosure. Building and Environment, 34, 7-17. http://dx.doi.org/10.1016/S0360-1323(97)00073-5

COMSOL. (2007). COMSOL Multiphysics Quick Start and Quick Reference V.3.4. In Comsol Multiphysics. COMSOL AB. 
Ismail, A. R., Jusoh, N., Zulkifli, R., Sopian, K., \& Deros, B. M. (2009). Thermal Comfort Assessment : A Case Study at Malaysian Automotive Industry. American Journal of Applied Sciences, 6(8), 1495-1501.

Judkoff, R., Wortman, D., Doherty, B. O., \& Burch, J. (2008). A Methodology for Validating Building Energy Analysis Simulations.

Meckler, M. (1991). Indoor Air Quality Design Guidebooks. Lilburn, GA, USA: Fairmoont Press.

Mendonça, K. C., Abadie, M. O., \& Blondeau, P. (2012). Modeling Particle Distribution Using The Zonal Approach: Case Study of a Hospital Room. In Ventilation 2012 (pp. 1-6).

Met One Instruments Inc. (2001). MODEL GT-521 PARTICLE COUNTER OPERATION MANUAL GT-521-9800 Rev. D. NW Washington Blvd. Grant Pass, Oregon 97526.

Paul, T., Sree, D., \& Aglan, H. (2010). Effect of mechanically induced ventilation on the indoor air quality of building envelopes. Energy and Buildings, 42(3), 326-332. http://dx.doi.org/10.1016/j.enbuild.2009.09.010

Pryor, R. W. (2011). Multiphysics Modeling Using COMSOL: A First Principles Approach. Sudbury, Massachusetts: JONES and BARTLETT.

Robinson, S. (2007). Conceptual modelling for simulation Part I: definition and requirements. Journal of the Operational Research Society, 59(3), 278-290. http://dx.doi.org/10.1057/palgrave.jors.2602368

Rouaud, O., \& Havet, M. (2002). Computation of the airflow in a pilot scale clean room using K- "turbulence models ' les de turbulence K-" pour le calcul de Utilisation de mode ' coulement d' air dans une salle blanche a 1 ' e ' chelle pilote 1' e. International Journal of Refrigeration, 25, 351-361.

Shannon, R. E. (1975). Systems Simulation - The Art and Science. BBAA VI International Colloqium on: Bluff Bodies Aerodynamics \& Applications. NJ: Prentice- Hall.

Tian, Z. F., Tu, J. Y., Yeoh, G. H., \& Yuen, R. K. K. (2006). On the numerical study of contaminant particle concentration in indoor airflow. Building and Environment, 41, 1504-1514. http://dx.doi.org/10.1016/j.buildenv.2005.06.006

Wong, N. H., \& Huang, B. (2004). Comparative study of the indoor air quality of naturally ventilated and air-conditioned bedrooms of residential buildings in Singapore. Building and Environment, 39, 1115-1123. http://dx.doi.org/10.1016/j.buildenv.2004.01.024

Yau, Y. H., Chew, B. T., \& Saifullah, A. Z. a. (2012). Studies on the indoor air quality of Pharmaceutical Laboratories in Malaysia. International Journal of Sustainable Built Environment, 1(1), 110-124. http://dx.doi.org/10.1016/j.ijsbe.2012.07.005

Yu, B. F., Hu, Z. B., Liu, M., Yang, H. L., Kong, Q. X., \& Liu, Y. H. (2009). Review of research on air-conditioning systems and indoor air quality control for human health. International Journal of Refrigeration, 32(1), 3-20. http://dx.doi.org/10.1016/j.ijrefrig.2008.05.004

\section{Copyrights}

Copyright for this article is retained by the author(s), with first publication rights granted to the journal.

This is an open-access article distributed under the terms and conditions of the Creative Commons Attribution license (http://creativecommons.org/licenses/by/3.0/). 